\title{
Residential solar electricity adoption: how households in Sweden search for and use information
}

\author{
Jenny Palm ${ }^{1 *}$ (D) and Elina Eriksson ${ }^{2}$
}

\begin{abstract}
Background: As a renewable energy solution, photovoltaics (PVs) are crucial in the transition to a more sustainable energy system. Besides large PV installations, household adoption of PVs will be an important contribution to this transition. However, the adoption of PVs on a household level faces many barriers, with gathering and understanding information being one of the major barriers. The aim of this article is to do an in-depth analysis of how households search for and interpret information about PVs and to discuss how to reach different groups with information.

Methods: The results in this paper are based on three interview studies made between autumn 2013 and autumn 2016. In the first interview study, seven non-adopters of photovoltaics were interviewed. In the second study, seven adopters of photovoltaics were addressed. In the third study, a total of 44 households were interviewed, with a mix of non-adopters and adopters. In total, 58 households were interviewed.

Results: From the interviews, we developed four ideal types for PV adoption. The non-adopters use few sources of information, find the information complicated, and have a tendency to emphasize barriers rather than enablers for PV adoptions. The environmentally engaged adopters search a lot of information but find it difficult to know when they have enough or the right information. They also find information too technical and complicated and find it hard to compare quotes. The professionally skilled group easily accesses information but also experienced problems in comparing quotes and are critical to that many problems occur during the installation process. The accidental adopters more or less happen to get a PV system and needed little information. They usually took the offer from the provider first met.

Conclusions: We can conclude that when dividing the households into different ideal types, it is possible to detect what kind of information measures different groups need. To get a future increase of the number of installed PVs, it is important to develop different measures in parallel, to meet the needs from the different groups.
\end{abstract}

Keywords: Photovoltaics, Adopter, Households, Prosumers, Ideal type, Adoption process, Information, Peer effect

\section{Background}

As humanity is overstepping several critical planetary boundaries [1], the shift to more renewable energy is becoming increasingly important and time critical. Renewable energy technologies, such as photovoltaics (PVs), are an important component of this transition of the energy system. Potentially, PVs are sustainable technologies that can be used in the future without irreversibly damaging the earth's ecosystem. The rapid development and adoption of

\footnotetext{
* Correspondence: Jenny.palm@iiiee.lu.se

${ }^{1}$ International Institute for Industrial Environmental Economics (IIIEE), Lund

University, Box 196, SE-221 00 Lund, Sweden

Full list of author information is available at the end of the article
}

renewable energy technologies seems vital, and in this process, households can become important actors.

The number of consumers producing electricity at home, so-called prosumers [2], is rapidly increasing in many European countries including Sweden. The Swedish PV market share is so far not large, accounting for only $0.08 \%$ of electricity production in 2015 [3]. The yearly electricity production from Swedish PV systems are $800-1100 \mathrm{kWh}$ per installed kilowatt of peak PV power depending on location and orientation, which gives a yearly electricity production of 100-140 GWh with the installed capacity in 2015. This can be compared to the yearly electricity demand in Sweden of close to $140 \mathrm{TWh}$ during the recent 
years. The electricity system in Sweden is a centralized system, and the dominating sources are hydropower and nuclear energy.

Earlier studies of prosumers have discussed different drivers and needs, as well as barriers, for households to become prosumers [4-10]. Buying a PV system is a high-involvement decision, and there are studies that indicate that households are willing to invest cognitive effort in the decision-making process [11]. However, due to complexity in the adoption process of PVs, households are unlikely to have all the information required when taking a decision. Nonetheless, many do invest despite far from complete information, and we are interested in studying how these decisions are made and what information is important in this decision. In this article, we present results from three interview studies with in total 58 households in Sweden, where we analyze the start of the adoption process of PVs. The aim of this article is to analyze different strategies households have used when searching and interpreting information about PVs to discuss different measures that can enhance the information seeking process in the future. We will analyze where and how households search for information, if the information has been perceived as usable and enough, and if several information sources have been used. From that, we will discuss different ideal types of information seekers that we have discerned from the material and how to approach them.

\section{Earlier studies of motives and barriers when households decide to invest in PVs}

There is substantial research showing that attitudes influence purchasing behavior. But research also indicates that information plays a role even if this is less studied. By researching the information received by consumers, it is possible to also better understand their purchase behavior [12,13]. Information is also seen as more important for sustainable products, where consumers often are interested in seeking detailed information of the product. Lack of adequate information has also led to market failures [13]. On the other hand, when there is a lot of information available, the consumers can sometimes feel overwhelmed or less sure of how best to go about it. Some consumers rely solely on checking the labeling on products to inform their purchases. In relation to white goods energy, labeling has proven to have great impact on the choice and is trusted as objective quite often that is the only information the consumer gathers on a product [14]. In research on white goods, it has been shown that the consumers wanted singledimensional advice from a trusted independent source. If there are no labeling, the consumer will ignore the green criteria or simplify the process into a buy and not buy decision [15].
In information studies, two phrases are commonly used, information behavior and information practice. Information behavior often refers to how people need, seek, manage, give, and use information in different contexts. Information practices emphasize the role of contextual factors of information seeking, use, and sharing, which distinguish them from the more individualistic approach in information behavior. Information practice also see information seeking as a discursive action [16]. In our analysis, we have asked people how they searched for information and what kind of information they received, which makes it closer to the information behavior perspective. It also touches upon the practice perspective when peer effects are discussed, but we do not analyze that material in a situated action approach which is also characterizing the practice perspective [16].

Buying solar panels is a high-involvement decision where people usually invest both time and consideration before making a decision [11]. Adopting this kind of technology is a process that has been described as generally entailing the household to (a) collecting information about available options, (b) investigating their pros and cons, and (c) making and implementing the decision [17]. Although the decision-making process unquestionably includes these stages, Rogers' model has been criticized for its linearity. Shove [18] have for example demonstrated that household energy use is closely related to identity creation and the "image" a household wants to maintain. Understanding household assumptions and perspectives is thus crucial to understand how a household reasons when investing in a PV panel. Adoption of green technology such as PVs must be understood in relation to both the characterization of the technology as well as the social context in which an investment is made. The choices people make depend on the institutional, geographical, cultural, and temporal contexts in which the choices are made [19].

Spaargaren and van Vliet [20], taking the consumer perspective on the innovation process, reason in a similar way and claim that individuals choose what products to consume in particular social arrangements and not in isolation; consumption thus must be seen in its social context. They claim that people seek to partially integrate green practices into their daily lives. Actors prefer to bind their various social practices into a reasonably coherent unit. When a householder embraces a green lifestyle, this corresponds to a life story in which the actor is expressing who she/he is or wants to be; the life story serves to express this person's identity and selfnarrative. From this perspective, "lifestyle" is the degree of coherence found in a person's behavior, though modes of action in one context may differ from those adopted in others. 
In earlier research, important drivers have been identified to why people choose to invest in PVs [10]. The driver mentioned most often environmental concerns [4, 21-23]. Balcombe et al. [21] and Schelly [24] both suggest that environmental values alone are not enough, and are not always necessary, to motivate adoption of PVs. Another important motive is to save money by buying less electricity from the grid or selling own produced electricity $[4,6,7,10,22,23,25$, 26]. Other identified drivers in earlier research are that someone in the household has a technical interest to become self-sufficient in electricity and a symbolic reason and to show others that the family cares about the environment [4, 6, 10, 21, 23, 25].

In earlier studies, peer effects have also been highlighted as an important factor for households to invest in PVs [27]. Even though this might be important, few studies have made a thorough study of peer effects. Palm's [27] study focused on this, and the author specifically chose to analyze what effects peers such as relatives, friends, and neighbors have on the adoption of PVs. The main peer effect he finds is that peers function as a confirmation that PV works as intended and without hassle. It seems however as if peers do not add any new information or raise other questions besides the questions they are being asked. Palm also found that peer effects occurred through existing and close relationships rather than between neighbors who were not already acquainted. Passive peer effect (i.e., just seeing PVs) was less important than active effect (through direct interpersonal contact).

From a household perspective, it might be important to make an economically rational choice that can be justified to friends and neighbors [4, 28]. Due to complexity in the decision-making process, people are unlikely however to have all the required information [11]. Also, what is rational from a technical or economic perspective may not necessarily be true for individual users [29]. The assumption that households make such rational choices seems difficult to verify in practice $[4,30]$. In addition, although individuals might try to behave rationally, they are not always aware of all the alternatives on the market, or may be unable to collect and process the information [31], and thus focus on a smaller number of alternatives and consequences while ignoring others.

The goal for households is then often to achieve a result that is satisfactory, rather than calculating the expected results and risks and then making the most rational, optimal choice [32]. Some important issues that households have to consider are energy costs, the PV system's effect on the value of the house, local and global environmental aspects, and the value of a "clean" system or technology, as well as fees and tariffs related to the inspection and maintenance of a system [33, 34]. One factor affecting the low level of adoption in contemporary Sweden is the lack of consumer experience with, for example, solar panels and low-energy housing. Households simply do not know what solutions exist since they have no experience for example with PVs and simply do not know what to ask for [19]. This also contributes to the slow market expansion. When households in Sweden think about their energy system, being able to produce one's own electricity may not always be of central interest or even part of their mindset. Another drawback for investments in PV panels is that short-term outcomes will be negative, such as a high initial financial investment, time-consuming administrative procedures, and construction work. Positive outcomes are more abstract and partly manifest in the long term [11].

Next, we will discuss how households in Sweden gathered and used information when deciding to invest in PVs, but first, we will describe the material and methods used.

\section{Method}

The results in this paper are based on three interview studies made between autumn 2013 and autumn 2016. In the first interview study, seven non-adopters of photovoltaics were interviewed. In the second study, seven adopters of photovoltaics were addressed. In the third study, a total of 44 households were interviewed. Of these, three households considered buying PV panels, two were non-adopters, i.e., they had decided not to buy PVs, 25 were adopters and had bought but were waiting for installation, and 14 adopters already had PVs installed.

The respondents were recruited through several sources. In the first study, three residential areas were chosen in the Stockholm area with regard to a distribution of median income and through studying a solar map (showing possible annual insolation with respect to the position of the roof and the roof inclination). In all the three areas, the households potentially owned their own roof, and at least one side of their roof would be optimal for photovoltaics. In the three chosen areas, a questionnaire was distributed by knocking on doors. The main purpose with this questionnaire was to come in contact with households to interview. The households were given the option to fill it out directly or send the questionnaire in using a pre-stamped envelope. In the questionnaire, the respondents were asked to answer questions about their energy consumption, energy savings, and if they had considered photovoltaics. They were also asked if they would agree to be interviewed. In the end, six households were interviewed, with at least one household in each area. Furthermore, one more household was interviewed in another area, reached through personal contacts. 
In the second study, we sent out a request to participate in our study based on a distribution list of customers of a photovoltaic retail company. We also used suggestions of households we received from a network consisting of PV professionals.

In the third study, different methods were used to approach households. In 2015, we received a list from the Swedish Energy Agency with all households that had applied for subsidies to install PVs. We sent an email to 250 households all over Sweden and recruited 21 respondents from that. We then asked three different PV vendors to ask customers that had decided to buy panels if they would like to participate. We do not have an exact number of how many were asked, but around 60 households received the request. Of these, 13 respondents agreed to participate. We also advertised for participants on a well-known blog about PVs in Sweden ("Bengts villablogg," Bengt's Home Blog). We do not have any figures on how many saw this announcement, but through this, another ten households were recruited to the project. A total of 44 households agreed to participate. The respondents were widely geographically distributed, but most lived in central or southern Sweden.

In total, 58 households were interviewed. At six occasions, both adults are present; otherwise, it was just one. The most common was a man that agreed to be interviewed. On average, the households interviewed are middle-aged; their income and education level are higher than the Swedish average. Because this is a qualitative study, it is not possible to draw conclusions as to whether the interviewees are representative of the general population of Sweden. In Sweden, we also lack statistics on homeowners as prosumers.

\section{Age}

The average age of the interviewees was 58 , and their ages ranged from 32 to 81 .

\section{Income}

Earlier studies have demonstrated a relationship between household income and investments in PV systems [35-38]. However, that correlation was found for a specific policy and market context that required a large amount of upfront capital. The recent decrease in production costs and the introduction of policies to change the market (e.g., subsidies) made it possible for households with a different income status to invest in solar panels. In our sample, the income for all our households was higher than the Swedish average. The average income for households with two adults in Sweden was around 50,000 EUR/year for both periods [39]. Not all our households wanted to reveal their income. On average, the 30 households had an income of 85,000 EUR/year.

\section{Social status and education}

Fischer and Sauter [40] suggest that income is not the reason for the greater number of installations among higher earners, but instead that it is due to social status and education. Thirty-five households had a university degree, 11 had a high school degree, and 7 had elementary school or did not answer the question.

\section{Energy consumption}

The households' total consumption of electricity and heat varied greatly from 3000 to $30,000 \mathrm{kWh}$ per year. The differences were mainly due to the heating system installed, the size of the dwelling, and the size of the family.

The three studies have used different interview guides, but all three included questions concerning (a) background data, e.g., age, education, income, heating system, electricity consumption; (b) first contact with the concept of small-scale electricity production and the reason the households are interested; (c) how they got information and from whom; (d) information received on various products, regulations, and policies; and (e) lack of information (see Appendix for one example of interview guide).

We took notes during the interviews, which were recorded. These recordings were transcribed and then analyzed using meaning condensation: each transcript was read through, and passages from it were condensed into shorter statements that could be thematically analyzed [41]. In this paper, we have reanalyzed and compared the results relating to the early phase of the adoption process and how information was received and processed.

\section{Results}

The results from our three interview studies are presented below. We have developed four ideal types for how the adoption, or in one case the non-adoption, process developed in relation to where and how households search for information, how the information was understood, and if several information sources were used. The ideal type does not exist in reality but symbolize the characterization found when we started to compare how the households answered in relation to different questions. It was for example more common for those how in their professions worked close to issues relating to PVs to be more satisfied with existing information than laymen. Based on our findings, we created the ideal types and discuss how to approach the different types.

\section{The non-adopters}

The non-adopters had relatively low knowledge of the technology as such, and one example of this was the 
common mix-up between photovoltaics and solar heat panels, i.e., panels for producing electricity and producing heat respectively. This was apparent when they discussed panels they had seen on houses or commercial buildings. They also emphasize the problems they saw with PVs rather than discussing in terms of possibilities. This group felt for example uneasy when contemplating on putting them up on their roof, as if they were somehow breaching etiquette. They made clear that it would be a violation to the esthetics of their house, as in the following quote:

I simply don't think it looks good... on an old building. It is kind of sad, but I have to admit that I think it doesn't look good. (non-adopter 7)

This group was worried about how the PVs would fit into the local community and that their neighbors would not approve of the installation. They were unsure if it really was in line with the overall urban planning policy and current zoning plan for an area.

This group was also the most critical to information accessible for them. They thought it was hard to understand if PVs had turned into a stable technology or if it would develop much in the near future, making an investment today less profitable in the years to come. They also asked for more neutral information and problematized that the source for the information often was the suppliers:

I think that what would make me take the step, would be a good package deal, that someone independent could guarantee, for example the university or the energy authority or something like that... well, someone that had looked at different suppliers and packages and could say, "These are reasonable choices, we have looked at this, this is good." (non-adopter 5)

This group finds the information too technical, and it seemed that the plethora of information served to discourage potential buyers. The amount of technical information also hindered an investment.

\section{The environmentally engaged adopters}

This group expressed a clear environmental engagement that had led them to the interest in renewable energy in general and in PVs in particular. One couple described how an interest had grown over a longer period, where different occurrences finally led to an investment decision:

We had an interest, a small interest in environmental issues. So we started quite early... we found an article that included something about photovoltaics and people had started to talk about using it at home and so on. And I thought it was fun and interesting. We don't really have any need for it, because we have district heating and don't use electricity for heating. But it was more that we had some interest. And then my brother-in-law got PVs... and they bought an electrical vehicle (EV) too and then we talked with them and they thought PVs were good. And then we might also buy an EV in the future... And it is good for the environment... Yes, it was something like that, that we reasoned before deciding to buy. (Adopter 27b)

Within this group, households searched for a lot of information, and the Internet was the main source of information. Many mainly just "googled around" for a while and tried to discern what information was valid and to the point. Besides getting information from the firms installing photovoltaics, they also visited blogs, forums for DIY (do it yourself)-interested people, and municipal information pages as well as sites belonging to the Swedish Energy Agency. One adopter describes his search pattern like this:

On the web, in magazines, by friends, acquaintances, energy advisors, installers... I have searched a lot on the Internet, for instance Bengt's Home Blog. I have also got information from the energy advisor in Finspång municipality. (Adopter 24)

Some of the respondents also gathered information from attending exhibitions or initiatives where private persons open their home to show their energy investments, often organized by local energy advisors. At these events, they gathered brochures and information sheets from installers and third parties.

This group was quite reflective and critical to the information they found, even if they were not as critical as the non-adopters. They wanted to know more about what the photovoltaic panels were made of and whether or not the panels had a high environmental impact compared to the renewable energy they produced. Another tendency in this group was that they had a hard time knowing what information they needed before making a decision, as in the following quote from a respondent who felt that she/he had badgered the suppliers with lots of questions:

And then... in a way it is because I am curious and I don't want to take action on something that I don't fully understand. Then not everything that I have learned has been necessary to know about before making a decision. But I did not realize this until afterwards. (Adopter 34) 
This group found the information to be too technical and too focused on numbers that they did not understand. They even meant that a background in engineering often is necessary:

We looked around for a while, we have [large energy company] as a distributor, but they did not have any information that was accessible. There are many small suppliers, but it doesn't feel safe. If you're not an engineer, you can't understand the difference between the different types of panels. (Adopter 5)

This group asked for tenders from several suppliers, comparing them on price. At the time, several energy companies and photovoltaic suppliers had ads for fixed packages at a fixed price, and these were also used as a benchmark to compare offers. However, comparing competitors turned out to be very difficult in many cases. Some did not feel confident enough to even ask for tenders, as in the following quote:

Well, I don't know, it is hard to write an application, or tender, or whatever it's called, when you don't know what it is you're supposed to ask for, you know. (Adopter 57)

\section{The professionally skilled}

Another group was professionally working with energy issues, which also makes them act privately. The latter were very well informed:

I have rather good knowledge about the market. I have among other things worked with procurement of PVs for the municipality. (Adopter 16)

When they need to find information about something, this group finds it easily. The information available is also written in a way that appeals to this group:

It has been easy to find information. There is a lot. But it is often very technically advanced, with a lot of numbers and stuff. But you learn the terminology after a while. It has helped that I have a background in engineering. (Adopter 44)

At the time, several energy companies and photovoltaic suppliers had ads for fixed packages at a fixed price, and these were also used as a benchmark to compare offers.

It was mainly because their price was several thousand Swedish kronor better than those I compared with.... I could have looked for more offers, but no, you cannot go on forever. (Adopter 46)
Even if this group is knowledgeable in the area, finding a supplier was not a straightforward process. Fixed packages usually only included the photovoltaic panels and the converter, and not the cost for installing the panels and rewiring the electricity. Sometimes, the buyer needed to contract both someone to install the photovoltaics and someone to rewire the electricity separately. Furthermore, the information given by the suppliers is difficult to compare and confused also this group.

I checked with three or four options, but the information was scarce from the suppliers. One of the suppliers doesn't update their website. They are bad at calculating the costs for the installation. I chose the installer because they are geographically close. The price was okay, but the management was immature and messy. It felt disorganized. The installation took a whole week. (Adopter 26)

This group experienced that the market was still immature and that the suppliers sometimes did not know what was needed for a full installation. Different suppliers gave different information concerning the system as such or the regulations concerning connecting the system to the grid. It was simply difficult for the households to understand and keep track of the process and they needed to rely on and trust the installers.

\section{The accidental adopters}

In this group, the investment decisions were more haphazard and accidental. One example was a household who had encountered photovoltaics along the autobahn when traveling in Germany and then started having discussions within the household that it seemed to be a good idea. Later, when coming back to Sweden, they also ordered a PV system to be installed at their house. Another household told us that they were looking for an electric bicycle but ended up by installing PVs:

It was last spring, we were out looking for an electric bike. But then we passed the village of Holbo and there they were showing PV panels. It was a company that had an exhibition. And it ended up that we bought PVs, but no electric bike. (Adopter 39)

The characteristic for this group was that they did not spent a lot of time searching for information. They usually just used one source, and if that one confirmed their view that PVs was a good investment, they were satisfied.

Yes, it was an ad in a magazine. The magazine was targeted at homeowners. It was an ad that said that you could ask for an estimate of the cost for an installment, so I just did that. (Adopter 19) 
Another common source of information was through someone they knew, a relative or neighbor who provided all the information:

From our neighbor. We did not need to search for ourselves. We got all the information from him. And that was enough for us. (Adopter 38)

This group does not compare installers. They meet with one and establish such good relationship that they decide to go with that installer.

I went on a meeting at Kungsholmen, a small meeting, where the Green Party participated... and it was going to be about PVs and they had invited a guest from ETC, Egen El [an installation company]. And then I made direct contact with him, the installer, and then we simply hired them. (Adopter 48)

This group is content with the information they received from one single person.

\section{Summary of the characterization of the four ideal types}

The four ideal types have different characterization and differ in their demand for information. They also have different requirements in what kinds of information and advice they ask for in relation to PVs.

The non-adopters used few sources of information. They lacked knowledge of nuanced key words to use when searching information and had a hard time finding relevant and succinct information. This group has a tendency to emphasize barriers rather than enabler for PV adoptions. They experience the available information so complicated that it discourages this group to move on in the adoption process.

The environmentally engaged group searches a lot of information, and the Internet was their main source. This group found it hard to know if they have got enough information or if there was something missing. They used forums, some public agency pages, and supplier websites, but what became a hinder for the households was that they did not know when they had enough or the right information. This group experienced that the available information is too technical and complicated and does not really respond to the questions they have. This group criticized that the available information often was diffused by someone whose intention was to sell a solar system to the households. This made them distrust the information and made them wonder what was a commercial argument and what parts were more neutral facts. This was hard for them to assess. This group asked for tenders from several installation companies, but when receiving quotes that were not comparable, this was of no help in the decision-making process.
The professionally skilled group had easy to access information. Information was given in a language they understood, and even if they had not installed or worked with PV directly, they easily grasped the jargon. They asked for and compared tenders from several companies but experience several problems finding a company that delivered the smooth installation process they expected.

The accidental adopters more or less happen to get a PV system, without much effort to find information or without much knowledge. They used one source of information and talked to one provider. The neighbor was a common source, and the knowledge of this peer becomes vital for the amount and the correctness in the information.

\section{Conclusions}

More and more households in Sweden are showing interest in the adoption of PV panels. The households have been motivated by decreasing prices on PV panels, introduction of subsidies, possibilities to sell the electricity back to the grid, and increased visibility of PV panels on housetops which makes people curious about the technology. When people have started to take an interest, they have however different preconditions to find, access, and understand available information. For one group, the non-adopters, the information barrier becomes so high that it restricts them from continuing and de facto investing in PVs.

One way to reach the non-adopters could be to develop really easily accessible information such as labeling system for PV panels and mandatory certification for installation firms. This group does not want to have any deeper knowledge and wants a quick answer on what panel to choose. They however also need to be convinced that PVs are a good solution to start with, and in that, general information campaign could be a good start.

The environmentally engaged group does not need to be motivated to invest in PV panels. However, they would need more information from a third neutral party, like the Swedish Energy Agency. Information that is easily accessed and without too many technical descriptions and figures would be an improvement for them. This group would also benefit from a development of standardized quotes that are possible to compare.

There is a lot of information about PVs on the web that suits the professional group. They had no problem to find and understand the information. They also had problems to compare the offers from different suppliers, and they complained over hassle during the installation processes. This group would also benefit from a development of standardized quotes and mandatory certification for installation firms. If there were a web page where installation firms were rated and customers 
evaluated their experience with a company, this could also suit this group.

The accidental group has a potential to grow larger. This group has a tendency to prefer face-to-face information. As PVs are becoming more and more visible, it will most likely make more people reflect on the possibility of adopting PVs. When more people have invested in PVs, the peer effect might also become even more important than it already is. If more people have PVs, it will be more of a subject for discussion in people's everyday lives, and through these mundane conversations, more persons will be informed about the possibilities and start reflecting on the feasibility of buying PV for themselves, and this peer effect will increase over time. This process will however be dependent on the peers having accurate and enough information to diffuse and their own positive experience to share. Otherwise, this can also become a barrier in the diffusion process.

The Swedish market is still immature, and information is still under development. To divide the market into different target groups is an important way to understand what kind of measures that need to be implemented. All groups here discussed are important to reach for the future; they just need slightly different approaches.

\section{Appendix}

Interview guide, example
Name
Age
Education
Work
Income
Family size
Heating system
How long have you lived in the house? How big is the house?

Electricy consumption? Heat consumption?

Hourly meeting? Both consumption and production?

How did you come up with idea to invest in solar panels? Who? When?

How did you get information on solar panels in general? What products to choose between?

Where did you find information?

How did you search for information?

Did you use several sources? Which in such case (magazines, friends, neighbours, energy advisors, authorities, energy companies, installers, suppliers...)

What kind of information did you get?

What kind of information do you lack?

Do you know how the PV system works? Do you need to know that? What would you like to know? What do you not need to have information about?

What have been your driving forces to invest in PVs?
Have you recieve subsidies? Did you use ROT? How have that process worked?

Which contacts have you needed to take to be able to install PVs

- Retailers

- Installers

- Energy companies (sale, grid)

- Taxation authority

- County administrative board

- Local authorities (building permit)

- Other authorities

- Others

What barriers have you experienced?

When have it been as most resistence in the adoption process? How? Why? How to avoid?

Which product did you choose? Why did you choose the product you did?

How big is the solar system? How much does it produce? As expected?

Do you sell electricity back to the grid? How much are you paid? How do you have contract with? Could you negotiate your price? How long is the contract?

The energy companies' role in general. What kind of service do you get and what did you expect? What has been hard/easy?

Do you allow us to access your production and consumption data?

Anything else you want to add?

Can we come back to you for more questions if needed?

Funding

The research presented in the paper was funded by the Swedish Energy

Agency under grant numbers 37511-1 and 37010-1.

Authors' Contributions

The two authors have contributed equally to all parts of the paper. Both authors read and approved the final manuscript.

Competing interests

The authors declare that they have no competing interests.

\section{Publisher's Note}

Springer Nature remains neutral with regard to jurisdictional claims in published maps and institutional affiliations.

\section{Author details}

IInternational Institute for Industrial Environmental Economics (IIIEE), Lund University, Box 196, SE-221 00 Lund, Sweden. ²Department of Media Technology and Interaction Design (MID), School of Electrical Engineering and Computer Science (EECS), KTH Royal Institute of Technology, SE-100 44 Stockholm, Sweden.

Received: 6 October 2017 Accepted: 3 April 2018

Published online: 07 May 2018

References

1. Steffen W, Richardson K, Rockström J, Cornell SE, Fetzer I, Bennett EM, Biggs R, Carpenter SR, de Vries W, de Wit CA, Folke C, Gerten D, Heinke J, Mace GM, Persson LM, Ramanathan V, Reyers B, Sörlin S (2015) Planetary 
boundaries: guiding human development on a changing planet. Science 347(6223). https://doi.org/10.1126/science.1259855

2. Toffler A (1980) The third wave. Collins, London

3. IEA PVPS PVPS annual report 20152015

4. Palm J, Tengvard M (2011) Motives for and barriers to household adoption of small-scale production of electricity: examples from Sweden. Sustainability: Science, Practice, and Policy 7(1):6-15

5. Keirstead J (2007) Behavioural responses to photovoltaic systems in the UK domestic sector. Energy Policy 35(8):4128-4141. https://doi.org/10.1016/j. enpol.2007.02.019

6. Balcombe P, Rigby D, Azapagic A (2014) Investigating the importance of motivations and barriers related to microgeneration uptake in the UK. Appl Energy 130:403-418

7. Islam T (2014) Household level innovation diffusion model of photo-voltaic (PV) solar cells from stated preference data. Energy Policy 65:340-350. https://doi.org/10.1016/j.enpol.2013.10.004

8. Luthander R, Widen J, Nilsson D, Palm J (2015) Photovoltaic selfconsumption in buildings: a review. Appl Energy 142:80-94. https://doi. org/10.1016/j.apenergy.2014.12.028

9. Palm A (2016) Local factors driving the diffusion of solar photovoltaics in Sweden: a case study of five municipalities in an early market. Energy Research \& Social Science 14:1-12. https://doi.org/10.1016/j.erss.2015.12.027

10. Palm J (2018) Household installation of solar panels - motives and barriers in a 10-year perspective. Energy Policy 113:1-8. https://doi.org/10.1016/j. enpol.2017.10.047

11. Jager W (2006) Stimulating the diffusion of photovoltaic systems: a behavioural perspective. Energy Policy 34(14):1935-1943

12. De Pelsmacker $P$, Janssens W (2007) A model for fair trade buying behaviour: the role of perceived quantity and quality of information and of product-specific attitudes. J Bus Ethics 75(4):361-380. https://doi.org/10. 1007/s10551-006-9259-2

13. Cerri J, Testa F, Rizzi F (2018) The more I care, the less I will listen to you: how information, environmental concern and ethical production influence consumers' attitudes and the purchasing of sustainable products. J Clean Prod 175:343-353

14. McDonald S, Oates C, Thyne M, Alevizou P, McMorland LA (2009) Comparing sustainable consumption patterns across product sectors. Int J Consum Stud 33(2):137-145

15. Oates C, McDonald S, Alevizou P, Hwang K, Young W, McMorland LA (2008) Marketing sustainability: use of information sources and degrees of voluntary simplicity. J Mark Commun 14(5):351-365

16. Savolainen R (2007) Information behavior and information practice: reviewing the "umbrella concepts" of information-seeking studies. Libr Q 77(2):109-132

17. Rogers EM (2003) The Diffusion of Innovations. Fifth Edition. The Free Press, New York

18. Shove E (1998) Gaps, barriers and conceptual chasms: theories of technology transfer and energy in buildings. Energy Policy 26(15):1105-1112. https://doi. org/10.1016/S0301-4215(98)00065-2

19. Palm J (2013) The building process of single-family houses and the embeddedness (or disembeddedness) of energy. Energy policy 62:762-767. https://doi.org/10.1016/j.enpol.2013.08.018

20. Spaargaren G, Van Vliet B (2000) Lifestyles, consumption and the environment: the ecological modernization of domestic consumption. Environmental politics 9(1):50-76

21. Balcombe P, Rigby D, Azapagic A (2013) Motivations and barriers associated with adopting microgeneration energy technologies in the UK. Renew Sust Energ Rev 22:655-666

22. Enlund T, Eriksson E (2016) Förnybar energi för alla. Slutrapport Green Leap, KTH. KTH, Green Leap, Stockholm

23. Wittenberg I, Matthies E (2016) Solar policy and practice in Germany: how do residential households with solar panels use electricity? Energy Research \& Social Science 21:199-211. https://doi.org/10.1016/j.erss.2016.07.008

24. Schelly C (2014) Residential solar electricity adoption: what motivates, and what matters? A case study of early adopters. Energy Research and Social Science 2:183-191. https://doi.org/10.1016/j.erss.2014.01.001

25. Juntunen JK (2014) Domestication pathways of small-scale renewable energy technologies. Sustainability: Science, Practice, and Policy 10(2):4-18

26. Shwom R, Lorenzen JA (2012) Changing household consumption to address climate change: social scientific insights and challenges. Wiley Interdiscip Rev Clim Chang 3(5):379-395. https://doi.org/10.1002/wcc.182
27. Palm A (2017) Peer effects in residential solar photovoltaics adoption-a mixed methods study of Swedish users. Energy Research and Social Science 26:1-10. https://doi.org/10.1016/j.erss.2017.01.008

28. Henning A (2000) Ambiguous artefacts: solar collectors in Swedish contexts. On Processes of Cultural Modification, Almqvist \& Wiksell International

29. Bartiaux F (2008) Does environmental information overcome practice compartmentalisation and change consumers' behaviours? J Clean Prod 16(11):1170-1180. https://doi.org/10.1016/j.jclepro.2007.08.013

30. Klintman M, Mårtensson K, Johansson M (2003) Bioenergi för uppvärmninghushållens perspektiv. Department of Sociology Lund University, Lund

31. March JG (1994) Primer on decision making: how decisions happen. Free Press, New York

32. March JG, Heath C (2009) A primer on decision making: how decisions happen. Free Press, New York

33. Palm J (2011) Energy efficiency in households: policy, implementation and everyday activities. Nova Science Publishers, New York

34. Stridh B, Yard S, Larsson D, Karlsson B (2014) Profitability of PV electricity in Sweden. 2014 IEEE 40th Photovoltaic Specialist Conference (PVSC), ate: 1492-1497. https://doi.org/10.1109/PVSC.2014.6925198

35. Abu-Arqoub M, Issa GF, Shubita AF, Banna AA (2014) Demand-driven algorithm for sharing and distribution of photovoltaic power in a small local area grid. International Journal of Information Technology and Web Engineering 9(1):45-58. https://doi.org/10.4018/ijitwe.2014010104

36. Gallegos R, Tapia E, Romero S (2014) Impact of the subsidy on the electric rate in the use of renewable energy for net zero housing in Mexicali, Mexico. WIT Trans Ecol Environ 181:291-300. https://doi.org/10.2495/ElD140251

37. Jiang A, Zhu Y (2012) Impact of incentives and system efficiency on the life cycle cost of photovoltaic systems. Int J Constr Educ Res 8(3):204-222. https://doi.org/10.1080/15578771.2011.615892

38. Schaffer AJ, Brun S (2015) Beyond the sun-socioeconomic drivers of the adoption of small-scale photovoltaic installations in Germany. Energy Research and Social Science 10:220-227. https://doi.org/10.1016/j.erss.2015.06.010

39. Statistic Sweden Hushållens ekonomi (HEK) 2014. http://www.scb.se/HE0103. Accessed 201611052016

40. Fischer C, Sauter R (2004) Users as pioneers: transformation in the electricity system, microCHP and the role of the users. In: Klaus Jacob, Manfred Binder and Anna Wieczorek (eds.). 2004. Governance for Industrial Transformation. Proceedings of the 2003 Berlin Conference on the Human Dimensions of Global Environmental Change, Environmental Policy Research Centre, Berlin, pp 319-337

41. Kvale S, Brinkmann S (2009) InterViews: learning the craft of qualitative research interviewing. Sage Publications, Los Angeles

\section{Submit your manuscript to a SpringerOpen ${ }^{\circ}$ journal and benefit from:}

- Convenient online submission

- Rigorous peer review

- Open access: articles freely available online

- High visibility within the field

- Retaining the copyright to your article

Submit your next manuscript at $>$ springeropen.com 